\title{
Cerebral Venous Thrombosis Presenting As Subarachnoid Hemorrhage: Clinical Case
}

\author{
Komi Igneza Agbotsou \\ Neurology Department of Bourg-en- Bresse Hospital Center, Bourg-en- \\ Bresse, France \\ Muriel Tchwa Tanoh Amon \\ Neurology Department of Bourg-en- Bresse Hospital Center, Bourg-en- \\ Bresse, France \\ Julian Paul Theodore Theuriet \\ Neurology Department of Bourg-en- Bresse Hospital Center, Bourg-en- \\ Bresse, France \\ Corinne Debras \\ Neurology Department of Bourg-en- Bresse Hospital Center, Bourg-en- \\ Bresse, France \\ Carlo Albanesi \\ Neurology Department of Bourg-en- Bresse Hospital Center, Bourg-en- \\ Bresse, France \\ Frederic Philippeau \\ Neurology Department of Bourg-en- Bresse Hospital Center, Bourg-en- \\ Bresse, France
}

Doi:10.19044/esj.2021.v17n21p27

Submitted: 08 November 2020

Accepted: 13 April 2021

Published: 30 June 2021
Copyright 2021 Author(s)

Under Creative Commons BY-NC-ND

4.0 OPEN ACCESS

Cite As:

Agbotsou K.I., Amon M.T.T., Theuriet J.P.T., Debras C., Albanesi C. \& Philippeau F. (2021). Cerebral Venous Thrombosis Presenting As Subarachnoid Hemorrhage: Clinical Case. European Scientific Journal, ESJ, 17(21), 27.

https://doi.org/10.19044/esj.2021.v17n21p27

\section{Abstract}

Subarachnoid hemorrhage is typically due to an aneurysmal rupture. Cerebral venous thrombosis is a rare cause, especially if the clinical presentation is atypical. We report a patient with unusual acute headaches, with an entirely normal physical examination. His cerebral MRI, and cerebral venous angio-MRI documented a cerebral venous thrombosis associated with 
subarachnoid hemorrhage. The outcome was favorable with anticoagulant treatment.

Keywords: Cerebral Venous Thrombosis, Subarachnoid Hemorrhage

\section{Background}

Cerebral venous thrombosis has an extremely variable clinical presentation. Headaches are the most common symptom, and found in about 80 percent of cases (Ameri and al, 1992). The occurrence of subarachnoid hemorrhage (SAH), in the context of cerebral venous thrombosis (CVT), is a rare. Only few cases are reported in the literature (Kato and al, 2010, Oppenheim and al, 2005). Subarachnoid hemorrhage is typically secondary to an aneurysmal rupture. Radiological studies, an essential aid, leads towards this often-unknown thrombophlebitis etiology. We report a case of cerebral venous thrombosis presenting as a subarachnoid hemorrhage, where the clinical and especially radiological presentation was atypical.

\section{Case presentation}

67-year-old retired man was, admitted for intense, unusual headaches of-acute onset. The pain was left frontal, accompanied by episodes of instability, obnubilation and without any motor deficit. In his history, he was hypertensive, well -controlled under hexatherapy, and well-balanced insulinrequiring type II diabetes. He suffered from chronic renal failure with a glomerular filtration rate around $30 \mathrm{ml} / \mathrm{min}$. He used a device for sleep apnea, and had stented coronary artery disease. The clinical examination showed a vigilant patient, time-oriented, and space-oriented, with no focal deficit, and no reflex disorder or meningeal syndrome. He was apyrexic. The blood pressure was normal, moderately obese with a BMI of $31 \mathrm{~kg} / \mathrm{m}^{2}$. Admitted urgently for these unusual headaches, he underwent a cerebral MRI. It showed a discrete left frontal cortical meningeal hemorrhage on the sequences in FLAIR and T2, with a cortical venous thrombosis on the T2 sequences, and the 3D T1 sequences with gadolinium injection. There was no arterial aneurysm, or objective arteriovenous malformation on the sequences with gadolinium injection (Figure 1). 


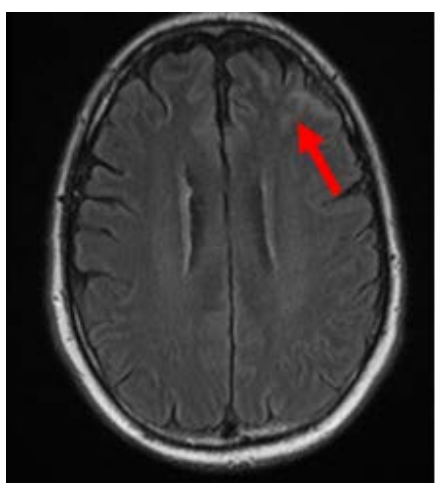

A : Axial T2 FLAIR

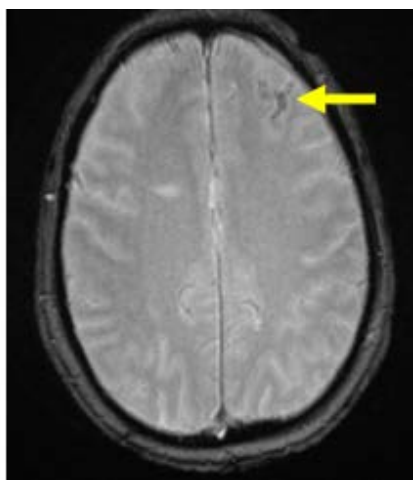

B : Axial gradient echo T2

Figure 1. Cerebral MRI axial T2 FLAIR (A), axial gradient echo T2 (B) and T1 with gadolinium injection (C), hemorrhage subarachnoid (T2 FLAIR and gradient echo T2) with left pre-frontal cortical venous thrombosis (T1 Gadolinium injection).

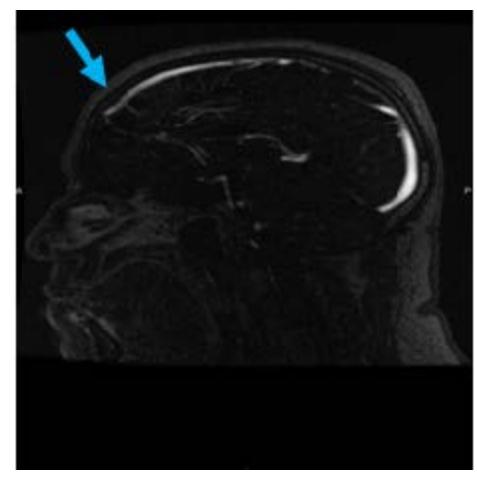

\section{$C$ : Axial T1 with gadolinium injection}

Figure 1. Cerebral MRI axial T2 FLAIR (A), axial gradient echo T2 (B) and T1 with gadolinium injection (C), hemorrhage subarachnoid (T2 FLAIR and gradient echo T2) with left pre-frontal cortical venous thrombosis (T1 Gadolinium injection).

The clotting system assessment was normal as well as the blood ionogram. A known renal failure was noted with a 212umol/l creatinine, and a glomerular filtration rate of $27 \mathrm{ml} / \mathrm{min}$. Blood glucose was $1.16 \mathrm{~g} / \mathrm{l}$ with glycated hemoglobin at $6.5 \%$ reflecting controlled diabetes. Cardiac enzymes at admission were negative. The TSH was normal. Homocysteine level was normal at 12.7. The autoimmune assessment was normal. There was no circulating lupus-like anticoagulant. The thrombophilia assessment was negative. Electrophoresis and immune-electrophoresis of serum proteins were normal. The lumbar puncture showed a clear fluid with an increase of red blood cells to $60 / \mathrm{mm}^{3}$, a high level of protein at $0.86 \mathrm{~g} / \mathrm{l}$ not considered significant in the context of diabetes; there was no decrease of the cerebrospinal fluid glucose. The IgG index in the cerebrospinal fluid was normal. The pathological examination of the CSF was normal. The diagnosis of pre-left frontal cortical venous thrombosis revealed by cortical meningeal 
hemorrhage was confirmed. In the absence of contraindication, the patient was put on heparin initially intravenous, and then switched to low molecular weight heparin in effective doses for a period of 3 months. It was switched to a platelet aggregating inhibitor due to the history of coronary stents. The evolution was marked by an nearly complete regression of headaches after 72 hours of heparin treatment, the improvement of renal function with a normal doppler of the renal arteries and a good perfusion of both kidneys. A second brain CT-scan on the 7th day of hospitalization showed the persistence of minim prefrontal cortical meningeal hemorrhage (Figure 2).

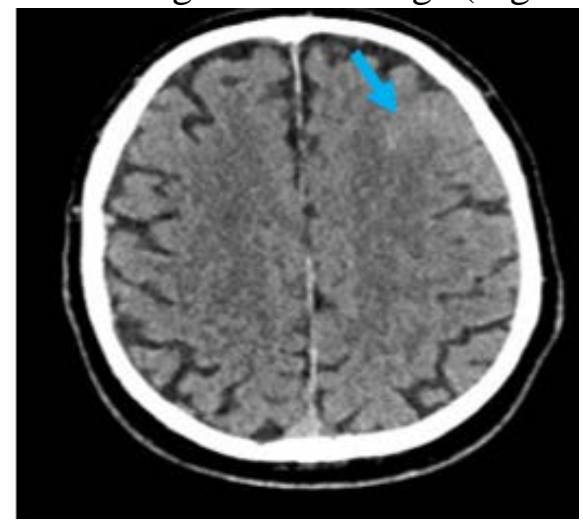

Figure 2. Brain CT-scan on the 7th day of Cerebral venous thrombosis with arachnoid hemorrhage

\section{Discussion}

The clinical presentation of cerebral venous thrombosis is variable (Bousser and al, 2007). Headaches, a major symptom, are usually progressive and diffuse (Bousser and al, 2007). In some situations, such as in our patient, they are severe at onset, suggesting a subarachnoid hemorrhage. Convulsive seizures and neurological deficit, not found in this patient, are frequently associated with headaches, consciousness impairment and may lead to coma in the severe cases (Bousser and al, 2007). The frontal location, the absence of seizures and the absence of neurological deficit are atypical in this case.

Brain imaging, in particular brain MRI with venogram, can establish the diagnosis (Oppenheim and al, 2005). In this patient, brain MRI showed a discrete left frontal cortical meningeal hemorrhage on the FLAIR and T2 sequences. This particular distribution that spared the sylvian fissure, the anterior inter-hemispheric fissure, and other cortical fissure, is atypical for aneurysmal subarachnoid hemorrhage.

The etiologies in the few reported cases of cerebral venous thrombosis complicated by subarachnoid hemorrhage are hypercoagulation of Leiden factor II (Tidahy and al, 2004) and Leiden factor V mutation (Otmani and al, 2012). However, no hypercoaguability was found in this patient despite a 
thorough prothrombotic evaluation. The CSF examination was normal with negative inflammatory and autoimmune assessments. Historically, in $15 \%$ of cases no etiology is found for cerebral venous thrombosis (Ferro and al, 2004). These require long-term follow-up since an etiology can show up several months, or even years later (Behçet's disease, neoplasia, myeloproliferative syndrome) (Crassard and al, 2006).

Therapeutic management of cerebral venous thrombosis associated with intracerebral or subarachnoid hemorrhage is well established (Einhaupl and al, 1991). It starts with curative anticoagulation by intravenous heparin (Einhaupl and al, 1991). The prognosis depends on an early treatment. If treated effectively and early, cases evolve favorably. In a large series, $80 \%$ of patients had a good functional prognosis. The death rate ranged from 5\% to 10\% (Ferro and al, 2008).

\section{Conclusion}

Cerebral venous thrombosis should be considered in case of in cerebral hemorrhage with headache, after excluding a diagnosis of aneurysmal rupture. Cerebral venous thrombosis can be treated effectively and its management differs from that of aneurismal rupture.

\section{References:}

1. Ameri A, Bousser MG. (1992) Cerebral venous thrombosis. Neurol Clin. 10 (1): 87-111. Doi.org/10.1016/S0733-8619(18)30235-4

2. Kato Y., Takeda H., Furuya D., Nagoya H., Deguchi I., Fukuoka T., and al. (2010). Subarachnoid hemorrhage as the initial presentation of cerebral venous thrombosis.Intern Med. 49 (5): 467-70.Doi: 10.2169/internalmedicine.49.2789

3. Oppenheim C., Domigo V., Gauvrit J.Y., Lamy C., MackowiakCordoliani M.A., and al. (2005) Subarachnoid hemorrhage as the initial presentation of dural sinus thrombosis.AJNR Am J. neuroradiol. 26 (3) : 614-617.PMID: 15760875

4. Bousser M.G., Ferro J.M. (2007) Cerebral venous thrombosis: an update. Lancet Neurol. 6 (2): 162-70. Doi: 10.1016/S14744422(07)70029-7.

5. Tidahy E., Derex L, Belo M., Dardel P., Robert R., Honnorat J., Nighoghossian N., Trouillas P. (2004) Cerebral Venous Thrombosis Presenting as Subarachnoid Hemorrhage. Rev Neurol (Paris). 160 (4) : 459-61.Doi: 10.1016/s0035-3787(04)70930-3

6. Otmani H. EI., Moutaouakil F., Fadel H. (2012) Subarachnoid hemorrhage induced by cerebral venous thrombosis. Journal des Maladies Vasculaires. 37(6) : 323-325. Doi.org/10.1016/j.jmv.2012.08.004 
7. Ferro JM, Canhão P, Stam J, and al (2004) Prognosis of cerebral vein and dural sinus thrombosis: results of the International Study on Cerebral Vein and Dural Sinus Thrombosis (ISCVT). Stroke. 35 (3):664-670. Doi.org/10.1161/01.STR.0000117571.76197.26

8. Crassard I, Bousser MG, and al. (2006) Cerebral Venous Thrombosis : focus. Rev Med Interne. 27(2):117-24.Doi: 10.1016/j.revmed.2005.06.003

9. Einhaupl KM, Willringer A, Meister W, and al.(1991) Heparine treatment in sinus venous thrombosis. Lancet. 338 (8767) :597-600. Doi.org/10.1016/0140-6736(91)90607-Q

10. Ferro JM, Canhao P. (2008) Complications of cerebral vein and sinus thrombosis. Front Neurol Neurosci. 23:16171.Doi.org/10.1159/000111377 